MONTANHINI NETO, R. e OSTRENSKY, A. Revisão: Uso de modelos matemáticos para avaliação da influência de variáveis ambientais sobre o desenvolvimento de ostras no Brasil. PUBVET, Londrina, V. 6, N. 4, Ed. 191, Art. 1284, 2012.

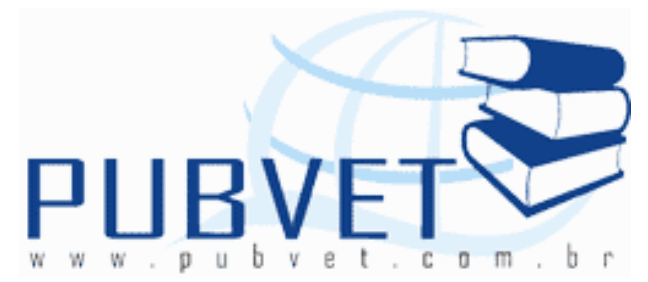

PUBVET, Publicações em Medicina Veterinária e Zootecnia.

\title{
Revisão: Uso de modelos matemáticos para avaliação da influência de variáveis ambientais sobre o desenvolvimento de ostras no Brasil
}

\author{
Roberto Montanhini Neto ${ }^{1 *}$ e Antonio Ostrensky ${ }^{2}$
}

${ }^{1 *}$ Médico Veterinário, Mestre em Ciências Veterinárias, Universidade Federal da Paraná, Curitiba-PR. E-mail: rmnvet@yahoo.com.br

2 Professor Doutor, Departamento de Zootecnia, UFPR, Curitiba-PR.

\section{Resumo}

A produção ostras nativas é uma atividade geradora de renda, que contribui na conservação dos estuários, diminuindo a pressão sobre os estoques naturais e promovendo uma exploração sustentável. O conhecimento das variáveis ambientais, fatores sazonais e a caracterização do desenvolvimento zootécnico e ciclo reprodutivo dos animais são determinantes para o sucesso técnico e econômico do cultivo. Em posse destes parâmetros, é possível criar modelos matemáticos que permitam compreender a relação desses bivalves com o ambiente e condições de cultivo, possibilitando assim orientar na tomada de decisão de produtores, gestores públicos e pesquisadores, na adequação de suas estruturas produtivas ao ecossistema aos quais estão inseridos. A presente revisão tem por objetivo apresentar um panorama técnico sobre cultivos de ostras nativas, a relação destes com os aspectos do ambiente e de como a modelagem matemática pode se consolidar como uma ferramenta efetiva para integrar estes dados.

Palavras-chave: ostreicultura; regressão múltipla; sistemas de cultivo 
MONTANHINI NETO, R. e OSTRENSKY, A. Revisão: Uso de modelos matemáticos para avaliação da influência de variáveis ambientais sobre o desenvolvimento de ostras no Brasil.

PUBVET, Londrina, V. 6, N. 4, Ed. 191, Art. 1284, 2012.

\title{
Use of mathematic models to evaluate the environment variables influence on productive development of cultivated oysters
}

\begin{abstract}
The native oyster production is an economic activity that contributes to the preservation of estuaries, reducing pressure on wild stocks and promotes a sustainable exploitation. Knowledge of the environment variables, seasonal factors and the characterization of livestock development and reproductive cycle are essential for the technical and economic success. Based on these parameters, it is possible to develop mathematical models for understanding the relationship of these bivalves to the environment and rearing conditions, thus enabling guidance for decisions of producers, public administrators and researchers, in adapting their productive facilities to the ecosystem where they are inserted. This review aims to present a technical overview of native oyster's production, their relationship with environment factors and how mathematical modeling can be consolidated as an effective tool to integrate these data.
\end{abstract}

Keywords: oyster production; multiple regression; farming systems

\section{INTRODUÇÃO}

A maricultura, que envolve o cultivo de moluscos, algas, crustáceos e peixes marinhos e estuarinos, é uma atividade que tem adquirido importância em diversos países de vasta orla marítima, como significativa fornecedora de proteína animal. Isso se dá pelos baixos custos de produção e pelo fato de proporcionar uma rentabilidade satisfatória. Dentre esses países, ocupam posição de destaque a China, Espanha, Nova Zelândia, Chile, Japão, Itália e Brasil (SOUZA-FILHO, 2003).

No Brasil, o cultivo de moluscos bivalves marinhos possui maior representatividade, por meio da produção de ostras e mexilhões, sendo os principais estados produtores São Paulo, Rio de Janeiro, Espírito Santo, Santa Catarina e Paraná. O país se destaca na produção destes organismos em razão 
MONTANHINI NETO, R. e OSTRENSKY, A. Revisão: Uso de modelos matemáticos para avaliação da influência de variáveis ambientais sobre o desenvolvimento de ostras no Brasil. PUBVET, Londrina, V. 6, N. 4, Ed. 191, Art. 1284, 2012.

da existência de condições oceanográficas favoráveis ao cultivo, tais como inúmeras áreas protegidas, compostas por baías, enseadas e estuários, além de aspectos também favoráveis de qualidade da água ao desenvolvimento biológico destes bivalves (ARANA, 2004; IBGE, 2007).

O cultivo de ostras tem se mostrado uma atividade viável em vários estados do litoral brasileiro. A produção de ostras, seja através da sua extração em bancos naturais ou da implantação de estruturas de cultivo, é uma fonte de renda importante para a economia de comunidades situadas ao longo da costa brasileira (OSTRENSKY et al., 2008). Com frequência, estas comunidades têm relatado um decréscimo acentuado na produtividade pesqueira, buscando na aquicultura alternativas para geração de alimento e de renda, o que pode ser importante para o futuro desses grupos e da própria atividade pesqueira e nos estuários paranaenses (GIA, 2009).

A existência de espécies apropriadas ao cultivo (Crassostrea sp, Sacco 1897) abre novas fronteiras que permitem incrementar a produtividade $e$ solidificar a atividade, além de possibilitar a exportação de tecnologias desenvolvidas para outras regiões e países (VILANOVA e CHAVES, 1988). Inicialmente, as ostras eram extraídas sem qualquer controle ou planejamento, a partir de bancos naturais, e vendidos sem padronização de tamanho comercial ou ainda como sementes (ERSE e BERNANDES, 2008).

O desenvolvimento futuro da maricultura como atividade econômica no litoral brasileiro passa por um momento importante, no qual a demanda vem gradativamente aumentando e a oferta vem em constante busca do equilíbrio (FERREIRA, 2006).

Apesar do imenso potencial natural, a estruturação dessa cadeia produtiva acabou ocorrendo de forma muito precária e frágil, o que tem colocado em risco a sustentabilidade técnica, econômica e ambiental dos empreendimentos instalados na região. Pouco foi estudado sobre a influência dos recursos ambientais disponíveis aos cultivos e com que maneira a variabilidade destes recursos afetaria a produtividade (ANDRIGUETTO FILHO e MARCHIORO, 2002). Torna-se imperativo o conhecimento das variáveis ambientais que interferem 
MONTANHINI NETO, R. e OSTRENSKY, A. Revisão: Uso de modelos matemáticos para avaliação da influência de variáveis ambientais sobre o desenvolvimento de ostras no Brasil. PUBVET, Londrina, V. 6, N. 4, Ed. 191, Art. 1284, 2012.

no desenvolvimento das ostras e o grau de influências destes fatores (GIA, 2009).

Atualmente, não é possível desenvolver projetos em aquicultura como uma atividade, sem considerar o custo da influência ambiental sobre os parâmetros zootécnicos dos cultivos (SILVA, 2004). É preciso ter clareza de que a produção a realizar-se tem que ser coerente com a realidade ambiental em que se desenvolve o processo produtivo, reconhecendo que as relações estabelecidas entre as diversas funções produtivas e destas com o ambiente não são puramente econômicas, mas que existem aspectos tecnológicos, ambientais e biológicos que são determinantes da ação que se quer realizar (POLI, 1998).

O grande desafio da cadeia produtiva da ostra é aumentar a oferta do produto e de modo continuado. Para alcançar estas metas, dentre outras prioridades, faz-se necessária a introdução de novos equipamentos e processos operacionais, adaptados às características biológicas da ostra nativa e às condições ecológicas dos corpos d'água estuarinos (PORTELLA, 2005). O conhecimento das características fisiológicas e ecológicas da ostra nativa, juntamente com programas de seleção e melhoramento genético eficientes, é fundamental para o desenvolvimento da produção da ostra nativa em mar aberto, representando uma alternativa de renda para pescadores artesanais e produtores locais, além de diminuir o impacto ambiental e os conflitos da atividade dentro das baías (BRITO, 2008).

Para casos como este, modelos matemáticos têm sido apontados como ferramentas necessárias para a melhor compreensão e representação da natureza (SANTOS e GRECA, 2005). Por definição, modelagem é a descrição matemática, por meio de equações, de diferentes fenômenos biológicos, tomando como base as variáveis quantitativas, para representar fatores que influenciam estes fenômenos, possibilitando prever as consequências da modificação de um ou vários parâmetros sobre o comportamento do sistema (RONDON et al., 2002). 
MONTANHINI NETO, R. e OSTRENSKY, A. Revisão: Uso de modelos matemáticos para avaliação da influência de variáveis ambientais sobre o desenvolvimento de ostras no Brasil. PUBVET, Londrina, V. 6, N. 4, Ed. 191, Art. 1284, 2012.

Com o desenvolvimento de modelos matemáticos de predição de resultados zootécnicos, permitem-se avaliações prévias de desempenho produtivos em diferentes sistemas de produção, em detrimento aos parâmetros ambientais pertinentes aos sítios onde se pretende implantar o cultivo, além de estimativas de produtividade do cultivo ao longo do ano (HENRIQUE, 2002). Em posse destas informações, os produtores poderão ter maior precisão nos cálculos de viabilidade de projetos de ostreicultura a serem implantados (ALVARENGA e NALESSO, 2006).

Busca agregar informações técnicas aos conhecimentos sobre sistemas de cultivo de ostras e a relação destes com os aspectos do ambiente, permitindo aos produtores adequação de suas estruturas produtivas ao ecossistema ao qual estão inseridos.

Além dos conhecimentos acima referidos, com o artigo pretende-se difundir conhecimentos bibliográficos sobre nossos ecossistemas estuarinos, além de contribuir com informações para a elaboração de projetos sócio-econômicoculturais de desenvolvimento da maricultura nacional.

\section{REVISÃO BIBLIOGRÁFICA}

\section{Maricultura e Ostreicultura no Brasil}

A maricultura é reconhecida mundialmente pela Organização de Agricultura e Alimento das Nações Unidas (FAO/ONU) como uma importante alternativa de geração de emprego, de renda e alimento, que tem contribuído para a fixação de comunidades tradicionais em seus locais de origem. $O$ esgotamento dos estoques de recursos pesqueiros, decorrente do excessivo esforço de pesca observado mundialmente, exige que todos os países elaborem políticas de desenvolvimento sustentável da maricultura, uma vez que essa atividade possui um enorme potencial de contribuição para o desenvolvimento social da zona costeira (FAO-SOFIA, 2002).

As atividades de pesca industrial causam efeitos que afetam negativamente a vida das comunidades, especialmente em áreas de frágil equilíbrio ambiental. A crescente preocupação dos governos e da sociedade civil em evitar estes 
MONTANHINI NETO, R. e OSTRENSKY, A. Revisão: Uso de modelos matemáticos para avaliação da influência de variáveis ambientais sobre o desenvolvimento de ostras no Brasil. PUBVET, Londrina, V. 6, N. 4, Ed. 191, Art. 1284, 2012.

impactos vem se manifestando na busca de alternativas que prosperem em um desenvolvimento que atenda às necessidades das comunidades, garantido melhores condições de vida, sem que para isso sejam ameaçados ou destruídos os recursos naturais e os bens culturais da região em questão (FAOSOFIA, 2002).

A maricultura representa a geração de instituições e sistemas capazes de controlar os recursos ambientais com mais eficácia, garantindo sua sustentabilidade e convivência harmônica com as demais atividades costeiras e aquícolas (FAO-SOFIA, 2002).

Segundo Pugialli (2000), "Ostreicultura" (do latim ostrea = ostra + cultura) é a atividade humana em que se cultivam ostras para o consumo humano. A produção destes moluscos encontra-se em segundo lugar no ranking das espécies aquícolas mais importantes no mundo (FAO, 2009), especialmente por envolver baixos custos para sua instalação, utilizar material de fácil obtenção, apresentar facilidade na captação de sementes e proporcionar índices satisfatórios de rentabilidade (BAUTISTA, 1989).

O cultivo de ostras, historicamente, data do início do império romano. Já no Brasil, é uma atividade relativamente recente, tendo sido iniciada em diversas partes do país no início da década de 1970. No período de 2000 a 2005, o Brasil obteve um aumento de $77 \%$ na produção de ostras, passando de 1.150 ton para 2.110 ton (IBGE, 2007).

Historicamente, quase todas as iniciativas de implantação de cultivos de ostras no Brasil foram originadas de Instituições Públicas de Pesquisa e Desenvolvimento Sócio-Cultural, com praticamente todo investimento por parte do poder público e pouco por parte dos produtores. Na maioria delas, não houve real participação das comunidades produtivas envolvidas, ficando a atividade restrita a pesquisas e tentativas de produção em escala experimental (FERREIRA, 2006).

A localização de bancos naturais de ostras em regiões de fácil acesso facilita o extrativismo, ocasionando uma intensa exploração, que pode levar a danos irreversíveis na estrutura populacional das espécies. Hoje a presença de ostras 
MONTANHINI NETO, R. e OSTRENSKY, A. Revisão: Uso de modelos matemáticos para avaliação da influência de variáveis ambientais sobre o desenvolvimento de ostras no Brasil. PUBVET, Londrina, V. 6, N. 4, Ed. 191, Art. 1284, 2012.

em tamanho comercial nos ambientes naturais locais já não é comum. Este fato ocorre basicamente nas comunidades ribeirinhas, onde a falta de informação e acesso a outros meios de subsistência é mais acentuado, agravando ainda mais a degradação dos ecossistemas locais com a captura descontrolada de organismos aquáticos (CHRISTO, 2006).

O cultivo de ostras ainda é uma atividade mista de extrativismo e maricultura, na qual os produtores coletam ostras juvenis nos bancos naturais em manguezais, e as transferem para estruturas de cultivo até que estas atinjam o tamanho comercial. Em alguns casos, as ostras são retiradas dos bancos naturais já com tamanho comercial e são apenas acondicionadas nas estruturas de cultivo para facilitar a comercialização. A maricultura propriamente dita, que envolve a produção de ostras a partir de sementes, ainda não é realizada e, da forma como esta vem sendo realizada, ela colabora para a redução dos estoques naturais e não difere muito de uma atividade essencialmente extrativista (GIA, 2009).

A preocupação com o efeito do extrativismo, como atividade econômica, sobre as populações de ostras não é recente. Cadernas (1984) relatou uma intensa exploração de bancos naturais de ostras na costa oeste do México. Enquanto que Mancera e Mendo (1996) demonstram indícios da exploração irresponsável, com métodos predatórios, de bancos naturais de ostras ocorrida na Colômbia.

Por outro lado, não se pode conceber o desenvolvimento de projetos de aquicultura em escala familiar que não estejam integrados aos planos de gerenciamento costeiro nacional e estadual e atrelados ao conceito de ecodesenvolvimento, principalmente com a proteção de recursos costeiros e com o saneamento ambiental (VINATEA e VIEIRA, 2005).

Embora esteja ocorrendo uma evolução acentuada na produção de ostras no Brasil, particularmente no estado de Santa Catarina, alguns avanços ainda precisam ocorrer para que a produção brasileira alcance os patamares dos grandes produtores mundiais. Há problemas relacionados às variações tecnológicas dos processos produtivos devido a diferentes características 
MONTANHINI NETO, R. e OSTRENSKY, A. Revisão: Uso de modelos matemáticos para avaliação da influência de variáveis ambientais sobre o desenvolvimento de ostras no Brasil. PUBVET, Londrina, V. 6, N. 4, Ed. 191, Art. 1284, 2012.

geográficas de cada local de produção e da inexistência de estudos acerca da determinação da real capacidade de carga das áreas de cultivo. A falta de desenvolvimento e transferência de tecnologias para a mecanização da produção impossibilita o aumento da produtividade das fazendas marinhas, e redução de custos de produção (BATALHA, 2002).

\section{Espécies de Ostras Encontradas e Cultivadas no Brasil}

A produção ostras nativas é uma atividade geradora de renda, que contribui na conservação dos estuários, diminuindo a pressão sobre os estoques naturais e promovendo uma exploração sustentável do ambiente (GUIMARÃES et al., 2008). No Brasil, destacam-se duas espécies de ostras nativas de interesse zootécnico, Crassostrea brasiliana (Lamarck, 1819) e C. rhizophorea (Guilding, 1828).

Ostras do gênero Crassostrea são moluscos bivalves pertencentes à família Ostreidae (RIOS, 1994). Habitam águas costeiras rasas, ocorrendo desde a faixa equatorial, entre as latitudes $64^{\circ} \mathrm{N}$ e $44^{\circ} \mathrm{S}$, até a faixa de frio moderado (WAKAMATSU, 1973; COSTA, 1985). As espécies deste gênero são consideradas eurihalinas e euritérmicas, desovam intermitentemente ao longo do ano e são adaptadas ao ambiente estuarino (GALVÃO et al., 2000; CHRISTO, 2006).

Possuem o corpo envolvido por duas conchas ou valvas articuladas em sua porção dorsal por um ligamento córneo. O corpo é composto por: conchas, músculo adutor, brânquias, manto, sistema digestivo, sistema circulatório e sistema nervoso. Possuem conchas de formato variável, usualmente alongada. A valva inferior ou esquerda é côncava, funda e encaixada sob a articulação (umbo), enquanto que a valva superior ou direita é plana. A cicatriz muscular é deslocada em direção dorso-lateral. Comparativamente as conchas são espessas, calcárias e frágeis. Habitam, geralmente, zonas de baixa salinidade (ISECMAR, 2007).

C. brasiliana só foi identificada no Brasil a partir da década de 1970 (Akaboshi e Pereira, 1981). Até então a espécie era identificada como $C$. 
MONTANHINI NETO, R. e OSTRENSKY, A. Revisão: Uso de modelos matemáticos para avaliação da influência de variáveis ambientais sobre o desenvolvimento de ostras no Brasil. PUBVET, Londrina, V. 6, N. 4, Ed. 191, Art. 1284, 2012.

rhizophorae, em função da enorme semelhança morfológica entre elas e ainda por possuírem os mesmos habitat e substrato de fixação. Porém, C. brasiliana apresenta melhor desempenho de crescimento durante o cultivo (Pereira et al., 2003).

Adultos de $C$. rizophorae e $C$. brasiliana são sésseis e apresentam grande plasticidade na morfologia da concha, dependendo do substrato onde estão fixados o que, de modo geral, acarreta controvérsias na identificação (VARELA et al., 2007; CHRISTO, 2006). Atualmente, pesquisas de diferenciação morfológica, molecular e produtiva dessas espécies vêm sendo desenvolvidas (PIE et al., 2006). Naturais de regiões estuarinas, a primeira é geralmente encontrada em costões rochosos e, também, em raízes de árvores de mangue (Rhizophora mangle). São predominantemente presentes no infralitoral, distribuindo-se desde o estado de Santa Catarina ao Pará (IGNÁCIO, 2000).

Absher (1989) observou diferenças nas taxas de crescimento e simpatria nas linhagens de morfologia larval de Crassostrea, sugerindo sua distinção em duas espécies (C. rhizophorae e C. brasiliana). Alves (2004), utilizando análises morfométricas e citogenéticas, observou que a morfologia de concha, a pigmentação da impressão muscular e a conformação dos tentáculos da borda do manto não forneceram dados suficientes para a diferenciação entre espécies. A citogenética, por sua vez, confirmou a presença das duas espécies citadas por Absher (1989), porém Alves (2004) questionou a posição que $C$. brasiliana e C. rhizophorae ocupariam na coluna d'água. Para este autor a espécie C. brasiliana habitaria a região entre-marés e C. rhizophorae o infralitoral, afirmações que vão de encontro ao descrito por Christo (2006).

Outra espécie de interesse zootécnico no Brasil é a ostra do Pacífico ( $C$. gigas). Esta espécie foi introduzida no país através de cultivos comerciais e, atualmente, tem se espalhado pelos habitats naturais da América do Sul, levantando preocupações sobre eventuais impactos ambientais desta espécie sobre os ciclos biológicos das espécies naturais de ostras (NIMPIS, 2002; ESCAPA et al.,.2004, CHRISTO 2006, MELO et al., 2009). 
MONTANHINI NETO, R. e OSTRENSKY, A. Revisão: Uso de modelos matemáticos para avaliação da influência de variáveis ambientais sobre o desenvolvimento de ostras no Brasil. PUBVET, Londrina, V. 6, N. 4, Ed. 191, Art. 1284, 2012.

Pie et al. (2006) diferenciaram as espécies C. brasiliana, C. rhizophorae e $C$. gigas pelo método de PCR-RFLP. Posteriormente, Varela et al. (2007) estudaram a identificação das espécies, estimando sua distribuição geográfica e estabelecendo as relações filogenéticas das espécies de Crassostrea. Segundo estes autores, a análise molecular (RFLP-PCR e o sequenciamento do $16 S$ rRNA) aliado a dados cariológicos revelaram a ocorrência de ostras do mangue (Crassostrea gasar, Adanson, 1757) ao longo do oeste da África e da costa atlântica da América do Sul. Os autores sugerem que a sequência do $16 \mathrm{~S}$ rRNA de $C$. brasiliana identificadas por Pie et al. (2006) seriam idêntica a de $C$. gasar (AJ312937) estudada por Lape 'gue et al. (2002).

Isto indica que $C$. brasiliana e $C$. gasar seriam a mesma espécie. Esta informação traz à tona algumas hipóteses, nas quais a espécie aqui denominada $C$. brasiliana seria exótica invasora e teria colonizado nosso litoral há muito tempo; que C. gasar seja a espécie invasora na costa Africana; ou ainda que, apesar do isolamento geográfico, com a separação dos continentes africano e americano, a espécie manteve suas características genéticas inalteradas.

Segundo Varela et al. (2007) o número de espécies de Crassostrea e sua distribuição no Brasil ainda não são totalmente conhecidos. No entanto, com o surgimento de novas ferramentas para a identificação de espécies, como é o caso da biologia molecular, por exemplo, novas informações têm auxiliado na diferenciação desses moluscos.

Outras espécies também são encontradas na costa brasileira e, eventualmente, tenham participação em cultivos baseados em recrutamento de larvas do ambiente. Varela et al. (2007) analisaram 120 espécimes coletados ao longo da costa brasileira, com o objetivo de identificar as espécies de ostras aqui presentes. Para identificação por técnicas de biologia molecular os animais estudados foram comparados com dados disponíveis no GenBank (BENSON et al., 2011). Além das espécies já identificadas e supra-citas, os autores encontraram outras espécies exóticas sem similaridade genética com os genomas conhecidos. López-Florez et al. (2010), a partir de caracterização 
MONTANHINI NETO, R. e OSTRENSKY, A. Revisão: Uso de modelos matemáticos para avaliação da influência de variáveis ambientais sobre o desenvolvimento de ostras no Brasil. PUBVET, Londrina, V. 6, N. 4, Ed. 191, Art. 1284, 2012.

molecular de diferentes espécies de ostras, sugerem que novas estirpes genéticas possam ser geradas por hibridação. Além do mais, Melo et al.(2010) questionam a não identificação taxonômica de algumas espécies encontradas na costa brasileira, além da constante introdução de espécies exóticas fixadas em cascos de navios mercantes.

\section{Condições Ambientais para Cultivo das Espécies de Ostras}

\section{Crassostrea brasiliana}

Habitam águas estuarinas, adaptados a substratos duros, sendo geralmente encontrados em costões rochosos e em raízes de árvore de mangue, predominantemente no litoral. Frequentemente, também são encontradas em fundos lodosos, onde conseguem também se desenvolver (LOPES, 2008). São bem adaptadas às zonas costeiras rasas (GALVÃO et al., 2000; CHRISTO, 2006).

Wakamatsu (1973) concluiu que C. brasiliana é capaz de sobreviver em salinidades de 8 a 34 UPS e tem um melhor desempenho na faixa de 15 a 25 UPS, classificando-a como uma espécie eurialina. Observações a campo mostram que a espécie está bem adaptada a viver em ambientes de grande variação de salinidade, suportando águas com salinidade muito próxima a zero por períodos relativamente curtos de tempo. Porém, em salinidades abaixo de 8 UPS as ostras fecham suas conchas e param de filtrar. Assim, tanto seu crescimento quanto reprodução são afetados pelas salinidades muito baixas (NASCIMENTO e PEREIRA, 2004). A sobrevivência de larvas também podem ser comprometida em salinidades abaixo de 8 UPS (NALESSO et al., 2008). Lemos et al. (1994) afirmaram que as larvas sobrevivem e crescem melhor em salinidades entre 25 a 40 UPS. Miranda e Guzenski (1999) concluíram que a melhor salinidade para a produção de sementes em laboratório varia de 25 a 30 UPS.

Ostras desta espécie demonstram preferência por águas com temperatura variando de 23 a $31^{\circ} \mathrm{C}$ (ANSA e BASHIR, 2007). Não há informações sobre as temperaturas mínimas suportadas pela espécie. 
MONTANHINI NETO, R. e OSTRENSKY, A. Revisão: Uso de modelos matemáticos para avaliação da influência de variáveis ambientais sobre o desenvolvimento de ostras no Brasil. PUBVET, Londrina, V. 6, N. 4, Ed. 191, Art. 1284, 2012.

\section{Crassostrea rhizophorae}

São indivíduos adaptados ao ambiente estuarino de turbidez elevada, devido à presença de uma câmara promial no lado direito do corpo que inverte a movimentação da água corrente exalante (GALTSOFF, 1964; GALVÃO et al., 2000).

Segundo Nascimento (1991), a faixa vertical adequada para fixação de $C$. rhizophorae nos manguezais fica entre 1 e 1,5 m acima da no nível 0,0 das marés de sizígia.

Guimarães et al. (2008) submeteram, em laboratório, juvenis de C. rhizophorae (altura $1,17 \pm 0,12 \mathrm{~cm}$ ) a salinidades entre de 5 a 60 UPS, com intervalo de 5 UPS entre cada tratamento. Os resultados mostraram que salinidades acima de 40 UPS são incompatíveis com sobrevivência de $C$. rhizophorae a partir do $4^{\circ}$ dia e recomendaram que os cultivos sejam realizados em áreas estuarinas com variação de salinidade entre 15 e 25 UPS. Os autores concluíram ainda que salinidades abaixo de 10 UPS e superiores a 30 UPS estão além dos limites de tolerância da espécie.

Fernandes e Sanchez (1980), analisando a tolerância de C. rhizophorae às baixas salinidades, concluíram que há um aumento das taxas de mortalidade em salinidades abaixo de 9 UPS, indicando que este ponto seria o limite para o osmoconformismo da espécie e que, a partir deste, a sobrevivência dependeria de uma eficiente regulação iônica.

Brito (2008) realizou testes para avaliação das taxas de crescimento em função da salinidade e concluiu que os maiores valores foram registrados ocorreram na salinidade de 25 PSU, que representa um valor médio típico de baías e estuários. No entanto, os resultados também revelaram que a ostra nativa pode crescer em salinidades mais elevadas, permitindo a produção em escala comercial fora das baías, em áreas de plataforma interna da região sul do Brasil.

A temperatura de conforto para a espécie $C$. rhizophorae está na faixa de 22,0 a $29,0{ }^{\circ} \mathrm{C}$, mas podem tolerar áreas com temperatura de até $34{ }^{\circ} \mathrm{C}$ 
MONTANHINI NETO, R. e OSTRENSKY, A. Revisão: Uso de modelos matemáticos para avaliação da influência de variáveis ambientais sobre o desenvolvimento de ostras no Brasil.

PUBVET, Londrina, V. 6, N. 4, Ed. 191, Art. 1284, 2012.

(BARLIZA e QUINTANA, 1992). O limite ótimo para a reprodução, segundo dos Nascimento e Pereira (2004), situa-se abaixo de $30^{\circ} \mathrm{C}$.

\section{Crassostrea gigas}

Os espécimes encontram-se nas zonas intermareais e de sublitoral superior, em áreas abrigadas, onde costumam ser encontradas até $3 \mathrm{~m}$ de profundidade. A ostras-do-Pacífico tem a capacidade de se fixar a praticamente qualquer substrato duro em águas abrigadas, mas, ocasionalmente, também podem ser encontradas em terrenos lamacentos ou de areia (NIMPIS, 2002).

A tolerância à salinidade e à temperatura de C. gigas variam enormemente, dependendo da variedade cultivada e da localização geográfica. Em termos gerais, pode ser considerada uma espécie marcantemente eurialina e euritérmica, que pode ser cultivada em águas oceânicas ou de estuários, com uma salinidade média de 15 PSU e valores tão baixos quanto 2 PSU. Nessas salinidades baixas, juvenis e adultos podem sobreviver por semanas, fechando suas válvulas (MIOSSEC et al., 2009).

Por outro lado, há cultivos na França que são realizados em salinidade de 45-50 PSU. Mortalidades são observadas acima de 50 PSU (HERAL e DESLOUS-PAOLI, 1990). Porém, é a combinação entre temperatura e salinidade que define as taxas de sobrevivência em condições ambientais adversas (GOULLETQUER, 1997). Da mesma forma, estado fisiológico e estágio de vida são fatores essenciais para determinar a tolerância da espécie às condições ambientais (POWELL et al., 2000 e 2002).

Akaboshi (1979) afirmou que C. gigas ocorre predominantemente em regiões de alta salinidade. Segundo Nehring (2006), são capazes de se reproduzir e crescer em salinidades de 10-42 PSU (23-36 PSU é a faixa ideal de salinidade para que ocorra a fertilização).

São capazes de crescer em temperaturas variando de 4 a $35{ }^{\circ} \mathrm{C}$ e sobreviver a temperaturas de até $-5^{\circ} \mathrm{C}$. No entanto, para que a reprodução é necessário que a temperatura seja superior a $20^{\circ} \mathrm{C}$. Mortalidade começa 
MONTANHINI NETO, R. e OSTRENSKY, A. Revisão: Uso de modelos matemáticos para avaliação da influência de variáveis ambientais sobre o desenvolvimento de ostras no Brasil. PUBVET, Londrina, V. 6, N. 4, Ed. 191, Art. 1284, 2012.

ocorrer a $30^{\circ} \mathrm{C}$ e a $40^{\circ} \mathrm{C}$ a mortalidade é de $100 \%$ após uma hora (NEHRING, 2006).

\section{Efeito das Variáveis Ambientais no Crescimento de Ostras}

Diversos parâmetros podem influenciar no sucesso da ostreicultura, tais como a técnica empregada, a biologia da espécie e seus requerimentos para o cultivo (PROENÇA, 2001). Outro fator diz respeito à qualidade da água, que influencia na fisiologia e na adaptação do animal ao ambiente (PEREIRA et al., 2003).

Poucos estudos investigam os impactos cumulativos de processos biológicos e ambientais e como eles contribuem para a mudança na estrutura da população de ostras (MILLER, 1983). Siqueira (2010) sugere o conhecimento sobre a influência desses fatores pode otimizar os esforços dos produtores em cada etapa do processo de cultivo de ostras nativas.

O conhecimento da qualidade das águas costeiras, assim como aspectos reprodutivos que permitem definir períodos de desova e maior recrutamento de larvas, são fatores importantes que permitem desenvolver metodologias seguras de cultivo (ERSE, 2008). Cardoso (2008) sugere a gestão participativa na definição do ordenamento da coleta de ostras, baseada nas experiências e aprendizados compartilhados pelos locais. Para tanto, é fundamental um diagnóstico do ambiente, dos atores sociais envolvidos e da maneira como estes interpretam os recursos, com os quais estão lidando (LOUREIRO et al., 2007).

Um fator de extrema importância quanto à implantação de projetos voltados para maricultura diz respeito à qualidade da água. A água constitui um dos compostos de maior distribuição e importância na superfície terrestre. Sua importância para a vida está no fato de que nenhum processo metabólico ocorre sem a sua ação direta ou indireta (ESTEVES, 1998).

Resultados sobre o crescimento da ostreicultura, principalmente entre os pequenos produtores, indicam uma falha no planejamento de cultivos e inadequação das águas destinadas à criação de organismos aquáticos 
MONTANHINI NETO, R. e OSTRENSKY, A. Revisão: Uso de modelos matemáticos para avaliação da influência de variáveis ambientais sobre o desenvolvimento de ostras no Brasil. PUBVET, Londrina, V. 6, N. 4, Ed. 191, Art. 1284, 2012.

marinhos. O conhecimento da qualidade da água, assim como aspectos ambientais que interferem no desenvolvimento dos moluscos, são fatores que permitem desenvolver metodologias seguras de cultivo (CHRISTO, 2006).

É na água, com suas propriedades físicas e químicas, onde estão contidos macro e micronutrientes, gases dissolvidos, sais, entre outros, que se faz necessária sua caracterização, bem como o monitoramento de suas variáveis ambientais. Dessa forma, faz-se necessário o monitoramento ambiental como critério decisivo para o sucesso do cultivo (RAMOS e CASTRO, 2004).

Os principais fatores relacionados à qualidade da água são a salinidade e a temperatura. Além desses fatores, também influenciam a concentração de oxigênio dissolvido na água, a dinâmica de correntes, o material particulado em suspensão (GALVÃo et al., 2000; SHUMWAY, 1996).

Segundo Vinatea (1999), a temperatura é um dos principais fatores limitantes numa grande variedade de processos biológicos, desde a velocidade de simples reações químicas até a distribuição ecológica de uma espécie animal. Esta variável desempenha um importante papel sobre os organismos aquáticos, afetando principalmente o crescimento, a taxa de alimentação, o metabolismo, a sobrevivência e a reprodução (CHAPARRO, 1998).

Miranda e Guzenski (1999), levando em consideração o crescimento em comprimento e a sobrevivência, obtiveram, nas condições em que foi realizado o experimento, como melhor resultado para o cultivo larval de C. rhizophorae, a temperatura de $25{ }^{\circ} \mathrm{C}$. Segundo os autores, esta temperatura é mais facilmente encontrada na costa brasileira, sendo que a temperatura de $22{ }^{\circ} \mathrm{C}$, em que se verificou mortalidade, é condição rara na região Nordeste.

Segundo Gomez et al. (1995), para seleção de área adequada para o cultivo de ostra do mangue, a salinidade da água deve estar entre 28 e 36 UPS (Unidade Padrão de Salinidade). Os mesmos autores sugerem que, para seleção de área adequada para o cultivo de ostra do mangue, a concentração de oxigênio dissolvido deve estar entre 2 e $5 \mathrm{mg} / \mathrm{l}$. Baixos níveis de oxigênio dissolvido são os maiores limitantes em aquicultura. Concentrações críticas de oxigênio podem ser alcançadas depois de maciça mortalidade do fitoplâncton e 
MONTANHINI NETO, R. e OSTRENSKY, A. Revisão: Uso de modelos matemáticos para avaliação da influência de variáveis ambientais sobre o desenvolvimento de ostras no Brasil. PUBVET, Londrina, V. 6, N. 4, Ed. 191, Art. 1284, 2012.

sua decomposição subsequente. A concentração crítica de oxigênio é de 1,5 $\mathrm{mg} / \mathrm{l}$, pois abaixo dela há uma redução drástica no crescimento dos organismos (BOYD e WATTEN, 1989).

Gomez et al. (1995) afirmam que as velocidades de correntes marinhas devem estar em torno de $30 \mathrm{~cm} / \mathrm{seg}$.; sugere que o efeito do turbilhonamento intenso gerado pelas correntes marinhas no local do cultivo possa influenciar o crescimento de $C$. rhizophorae. Isso pode causar estresse na ostra, uma vez que a elevação da concentração de material particulado contribui para o aumento da turbidez que, por sua vez, força a ostra a canalizar energia de crescimento para a filtração das partículas. Concomitantemente, o aumento desses sólidos propicia maior absorção da radiação, elevando a temperatura e diminuindo consequentemente a solubilidade do oxigênio.

$\mathrm{O} \mathrm{pH}$ é uma variável muito especial nos ambientes aquáticos, podendo influenciar muitos fenômenos químicos e biológicos. Seu efeito nos organismos cultivados se relaciona ao metabolismo e processos fisiológicos. Segundo Esteves (1998), o pH atua sobre as comunidades aquáticas diretamente nos processos de permeabilidade da membrana celular, interferindo, portanto, no transporte iônico intra e extracelular e entre os organismos e o meio. Para Gomez et al. (1995), o pH da água deve estar entre 7,9 e 8,1. Deduz-se que pequenas variações de $\mathrm{pH}$ não são representativas para afetar o crescimento da ostra, comparando-se aos intervalos de Vinatea (1997), que testou variações de 4 a 11 , as quais são consideradas, respectivamente, limites inferior e superior de sobrevivência.

A concentração de pigmentos fotossintetizantes é extensivamente utilizada para estimar a biomassa do fitoplâncton. Para o fitoplâncton a concentração destes pigmentos constitui aproximadamente, de 1 a $2 \%$ do peso seco (BARROSO e LITTLEPAGE, 1998).

A produtividade de um local é verificada, mediante a quantificação de clorofila a, como um índice de biomassa fitoplanctônica em determinado volume de água expresso em $\mathrm{mg} / \mathrm{m}^{3}$ (POLI, 1998). Ocorrem também produtos de degradação da clorofila a ("chla"), que são utilizados como indicadores 
MONTANHINI NETO, R. e OSTRENSKY, A. Revisão: Uso de modelos matemáticos para avaliação da influência de variáveis ambientais sobre o desenvolvimento de ostras no Brasil. PUBVET, Londrina, V. 6, N. 4, Ed. 191, Art. 1284, 2012.

indiretos de produtividade, que são os feoforbídeos e feofitinas constituindo os feopigmentos e os clorofilídeos (BARROSO e LITTLEPAGE, 1998). Segundo Agudo (1988), a determinação quantitativa da relação dos pigmentos fotossintetizantes (clorofila a e feofitina a) em ambientes aquáticos tem grande importância no estado fisiológico da comunidade fitoplanctônica.

Poli (1998) menciona que o valor mínimo da concentração de chla para ocorrer crescimento de ostras em regime de cultivo que é de $4 \mathrm{mg} / \mathrm{m}^{3}$. Verifica-se que a maioria das concentrações determinadas no trabalho citado encontrava-se abaixo desse valor, porém o crescimento das ostras manteve-se adequado.

Segundo Tureck et al. (2004), fazendo análise de regressão múltipla de dados de influência de variáveis ambientais sobre índices de tamanho de ostras $C$. gigas, observaram coeficientes significativos $(P<0,05)$ as variáveis de temperatura de água, salinidade, $\mathrm{pH}$ e teor de oxigênio dissolvido. Neste mesmo trabalho, os autores identificaram que cultivos em locais com maior estabilidade de variações de parâmetros ambientais apresentam índices de crescimento significativamente maiores quando comparados a cultivos em locais onde os mesmos parâmetros apresentam variações mais bruscas e constantes.

Em avaliação de componentes principais, Ramos e Castro (2004) verificaram que as variáveis ambientais que tiveram influências mais significativas no crescimento da ostra $C$. rhizophorae foram o material particulado em suspensão, velocidade de corrente, salinidade e oxigênio dissolvido. Processos metabólicos requeridos pela ostra neste ambiente seriam mais utilizados na filtração ao invés do crescimento, o que denotaria dispêndio maior de energia para a manutenção dos processos metabólicos dos organismos cultivados. Os autores sugeriram que elevadas amplitudes de marés, juntamente com as velocidades de corrente e a sazonalidade nessa área, sejam fatores dominantes agindo direta e indiretamente nos ecossistema, como também no comportamento das variáveis estudadas. 
MONTANHINI NETO, R. e OSTRENSKY, A. Revisão: Uso de modelos matemáticos para avaliação da influência de variáveis ambientais sobre o desenvolvimento de ostras no Brasil. PUBVET, Londrina, V. 6, N. 4, Ed. 191, Art. 1284, 2012.

\section{Efeito das Variáveis Ambientais na Reprodução de Ostras}

Em relação ao ciclo reprodutivo, a exploração comercial destes moluscos é direta e indiretamente influenciada pelas características sexuais das espécies cultivadas e pelos respectivos estímulos ambientais e sazonais que interferem no amadurecimento gonadal e na liberação de gametas (CLEDÓN et al., 2004). Os ciclos reprodutivos de bivalves marinhos estão intimamente relacionados à capacidade de armazenagem e utilização de energia e com os parâmetros ambientais como temperatura, salinidade e disponibilidade de alimento (TAYLOR e VENN, 1979; ZANDEE et al., 1980; BENINGER e LUCAS, 1984; ARELLANO-MARTINEZ et al., 2004; LI et al., 2006).

Vários trabalhos demonstraram que, em regiões subtropicais, o efeito de sazonalidade de temperatura, salinidade, fotoperíodo e níveis de clorofila da água interferem inexoravelmente o ciclo reprodutivo de ostras (STEPHEN, 1980; SAUCEDO et al., 2002; REN et al., 2003; FABIOUX et al., 2005; LI et al., 2006; DRIDI et al., 2007). A maioria destes autores caracteriza o ciclo reprodutivo em duas fases: uma fase de repouso nos meses de inverno e gametogênese, incluindo maturidade e de desova, na primavera e verão. Um novo ciclo de gametogênese inicia-se com temperatura da água baixa no final do inverno e início da desova ocorre no momento em que a temperatura da água e os níveis clorofila ficam mais elevados, em períodos de menor salinidade durante todo o ano.

\section{Conceito de Modelagem Matemática}

Os modelos são construídos para organizar a compreensão dos sistemas e idéias; avaliar os dados observados; fornecer o entendimento das ligações entre os componentes; definir os problemas, e; fazer previsões (ANGELINI, 2000). Segundo o autor, pode-se classificar os modelos em:

1) Modelos icônicos: reproduzem a aparência (imagens ou ícones) do objeto a ser modelado, fornecendo uma descrição apenas qualitativa, porém que sintetiza o todo. Exemplo: maquetes, mapas, diagramas de blocos, fluxograma, entre outros. 
MONTANHINI NETO, R. e OSTRENSKY, A. Revisão: Uso de modelos matemáticos para avaliação da influência de variáveis ambientais sobre o desenvolvimento de ostras no Brasil.

PUBVET, Londrina, V. 6, N. 4, Ed. 191, Art. 1284, 2012.

2) Modelos analógicos: simulam uma situação real. Possuem grau de abstração média e são usados principalmente em engenharia. Exemplo: pequenos modelos de avião postos à prova em túneis de vento.

3) Modelos matemáticos: conjunto de equações com grau de abstração máximo e representam princípios que (supostamente) regem a realidade. Exemplo: previsão meteorológica, determinação de exigências nutricionais, estudos de carga de sistemas.

Modelagem matemática é a abstração e simplificação da realidade capaz de integrar as principais interações e o principal comportamento do sistema estudado, apta a ser manipulada com o objetivo de prever as consequências da modificação de um ou de vários parâmetros sobre o comportamento do sistema (SPEDDING, 1988). A modelagem é, sobretudo, uma tentativa de integração de diferentes fenômenos, sendo limitada pelos recursos humanos e pelos materiais disponíveis e/ou utilizados na sua construção (LOVATTO e SAUVANT, 2001).

A modelagem computacional é uma alternativa para ajudar na tomada de decisões e na definição de produtos melhores e mais econômicos, tanto na indústria como na pesquisa (SPEDDING, 1988; BLACK, 1995).

O desenvolvimento de modelos que simulam processos fisiológicos, como o metabolismo basal e a deposição de tecidos, tornam-se necessários não só para o estudo e a compreensão destes processos biológicos, mas servem também como uma ferramenta para o aprofundamento nos processos envolvidos, assim como para a identificação de lacunas no conhecimento (McNAMARA et al., 2000).

Segundo Baldwin (1995), os modelos matemáticos podem ser classificados como: estáticos ou dinâmicos; determinísticos ou estocásticos, e; empíricos ou mecanísticos.

Os modelos estáticos descrevem o fenômeno em determinado momento ou instante, enquanto que nos modelos dinâmicos os parâmetros podem variar no tempo (LOVATTO e SAUVANT, 2001). 
MONTANHINI NETO, R. e OSTRENSKY, A. Revisão: Uso de modelos matemáticos para avaliação da influência de variáveis ambientais sobre o desenvolvimento de ostras no Brasil. PUBVET, Londrina, V. 6, N. 4, Ed. 191, Art. 1284, 2012.

Modelos determinísticos são aqueles que só têm uma única resposta, enquanto que nos modelos estocásticos (ou probabilísticos) possíveis respostas dependem de uma distribuição de probabilidade. Ao definir que as variáveis podem assumir valores amostrados ao acaso de uma distribuição de probabilidade, esses modelos podem ser considerados como exemplos de modelos estocásticos (RONDÓN et al., 2002).

Os modelos estocásticos permitem a estimação dos parâmetros de dispersão, os quais medem a variabilidade dos indivíduos que compõem a população (RONDÓN et al., 2002).

Os modelos empíricos são baseados apenas em correlações ou associações entre duas ou mais variáveis, sem levar em consideração os mecanismos que controlam o fenômeno. Por outro lado, os modelos mecanísticos tentam explicar ou descrever os mecanismos envolvidos, baseando-se nas leis da física, química, bioquímica, etc. (RONDÓN et al., 2002).

A dificuldade em se definir os mecanismos envolvidos nos fenômenos biológicos faz com que a maioria dos modelos propostos para produção animal sejam empíricos. Entretanto, é muito importante tentar desenvolver modelos mecanísticos que descrevam fenômenos, para se aprofundar nos conhecimentos dos processos envolvidos (FRANCE e THORNLEY, 1984; BALDWIN, 1995; McNAMARA et al., 2000).

Quanto mais detalhada for a descrição do processo, maior será o número de variáveis envolvidas no modelo, aumentando a complexidade do programa e a demanda computacional. Entretanto, a modelagem computacional pode ser o meio pelo qual o conhecimento obtido em fisiologia e metabolismo, por meio de minuciosos estudos do funcionamento de órgãos e células, seja utilizado para se evoluir o entendimento das funções animais e das fontes de variação do desempenho animal e finalmente no desenvolvimento de estratégias nutricionais, genéticas ou de manejo, que aperfeiçoem o retorno econômico (BALDWIN, 1995).

A modelagem é um processo que nos permite organizar as informações, identificar lacunas ou pontos fortes no conhecimento e pode ser útil na 
MONTANHINI NETO, R. e OSTRENSKY, A. Revisão: Uso de modelos matemáticos para avaliação da influência de variáveis ambientais sobre o desenvolvimento de ostras no Brasil. PUBVET, Londrina, V. 6, N. 4, Ed. 191, Art. 1284, 2012.

avaliação de políticas ou programas. É importante entender a modelagem como um processo e não como apenas uma maneira de chegar a uma resposta final. Há muitos tipos diferentes de modelos e abordagens de modelagem com algum ser muito simples e outros de alta complexidade, alguns podem ser puramente descritiva e alguns se esforçam para ser preditiva de alguma forma. No entanto, o processo de modelagem em si é um processo de abstração da realidade, a fim de simplificar as interações e relações entre diferentes componentes de um sistema, a fim de torná-lo mais facilmente compreendida. Ele é um método para lidar com os limites de nosso entendimento e os limites da disponibilidade de dados (LIDDEL, 2008).

A utilidade prática de um modelo de descrição de processos biológicos vai depender da sua interação com aspectos econômicos da indústria e da comercialização (RONDÓN et al., 2002).

A credibilidade dos modelos empregados nas simulações depende desses estarem baseados em dados provenientes de pesquisas que empregam métodos científicos de experimentação, os quais requerem avaliações por meio de metodologias estatísticas apropriadas. Dentre os procedimentos estatísticos empregados nas experimentações, as análises de regressão linear, não-linear ou múltipla merecem um importante destaque por serem bastante úteis na determinação da relação existente entre as variáveis respostas e os fatores considerados nos modelos. A quantificação dessas relações é fundamental para o processo de implantação dos programas de simulação (RONDÓN et al., 2002).

Para avaliação de um modelo, pode-se testá-lo em populações de comportamento conhecido ou com dados da literatura, além de outras formas. Segundo Harlow e Ivey (1994), quatro aspetos básicos precisam ser avaliados em cada modelo: a calibração, a acurácia, a precisão e a viés.

A calibração é o processo de ajuste dos parâmetros que permite ao modelo estimar o crescimento em condições comerciais. Cada modelo utiliza um método de calibração diferente, podendo influenciar sua flexibilidade e/ou confiabilidade (RONDÓN et al., 2002). 
MONTANHINI NETO, R. e OSTRENSKY, A. Revisão: Uso de modelos matemáticos para avaliação da influência de variáveis ambientais sobre o desenvolvimento de ostras no Brasil. PUBVET, Londrina, V. 6, N. 4, Ed. 191, Art. 1284, 2012.

A acurácia de um modelo determina quão próximo o modelo estima os dados de produção. A precisão do modelo está relacionada à variabilidade de suas respostas. Um modelo pouco preciso pode apresentar resultados muito variáveis para uma mesma condição. O viés do modelo indica as falhas sistemáticas para predizer os valores, o que pode levar a super ou subestimação de variáveis importantes (RONDÓN et al., 2002).

Segundo Angelini (2000), independentemente do tipo, a confecção de um modelo inclui as seguintes fases:

1) Reconhecer e delimitar o sistema de interesse, expressando-o de preferência por meio do diagrama conceitual, a fim de visualizar as interações entre os componentes;

2) Escolher a estrutura quantitativa geral (equações diferenciais, matriz algébrica, modelos de compartimento), selecionando ainda a unidade de tempo e codificando-a no computador para a realização das simulações;

3) Observar a validade do modelo, a fim de confirmar se é adequado para satisfazer os objetivos propostos. Esta fase compreende:

a) Análise de sensibilidade: mede-se a sensibilidade dos parâmetros, isto é, em que medida os parâmetros modificam os resultados do modelo e, consequentemente, do ecossistema;

b) Verificação-calibração: descobre-se que valores minimizam a diferença entre os dados observados e os calculados pelo modelo, e;

c) Validação: é o teste que o modelador fará para saber se os parâmetros encontrados na calibração são válidos para outros períodos do mesmo sistema.

$\mathrm{Na}$ verdade estas fases são muito parecidas com o próprio desenrolar de trabalhos científicos. Conforme Eco (1991), pode-se traçar um paralelo entre a confecção de um trabalho científico e a construção de um modelo. É importante notar que estas fases nem sempre se desenvolvem como o descrito. Muitas vezes, interagem devido a novas descobertas e problemas que vão surgindo à medida que o trabalho (ou o modelo) vai sendo construído. 
MONTANHINI NETO, R. e OSTRENSKY, A. Revisão: Uso de modelos matemáticos para avaliação da influência de variáveis ambientais sobre o desenvolvimento de ostras no Brasil.

PUBVET, Londrina, V. 6, N. 4, Ed. 191, Art. 1284, 2012.

\section{Uso de Modelos Matemáticos em Estudos de Ecossistemas}

O uso de quaisquer modelos matemáticos aplicados à Ecologia sempre foi motivo de ceticismo. É interessante notar que para os ecólogos na década de 20 o uso dos modelos poderia, além de ser uma nova ferramenta analítica, conferir certo grau de status à Ecologia que atingiria, então, o mesmo grau de exatidão das ciências físicas (ANGELINI, 2000). A equação de Verhulst, por exemplo, foi fervorosamente defendida por Raymond Pearl que estava particularmente interessado em encontrar uma lei (não apenas uma teoria) de crescimento das populações (KINGSLAND, 1985).

Porém, em 1934, Georgii F. Gause (citado por ANGELINI, 2000) demonstrou que os modelos não necessariamente teriam que prever os fenômenos e/ou processos com precisão. Esse cientista russo iniciou seus trabalhos em laboratório baseado nos modelos da curva logística e de presapredador. Sua descoberta do princípio de exclusão competitiva, no início conhecido como Postulado de Gause, mostrou que os modelos apenas serviriam para descobrir princípios e construir teorias gerais que guiariam certos tipos de pesquisas (como guiou as dele).

Segundo a Teoria dos Sistemas de von Bertalanffy (1934), dada a complexidade dos ecossistemas, usa-se a análise de sistemas para a sua compreensão, pois ela permite que fenômenos complexos sejam reduzidos em partes elementares, possibilitando a aplicação de métodos quantitativos.

A análise de sistemas, descrita por von Bertalanffy, é contemporânea do próprio desenvolvimento do conceito de ecossistemas e funcionou, num primeiro momento, como forma de estruturação do pensamento. Segundo Starfield e Bleloch (1986), um modelo é qualquer representação de um sistema ou processo, mas é a modelagem matemática que vem se transformando no instrumento mais eficaz da previsão de mudanças em ecossistemas.

Assim como os modelos matemáticos contribuíram com o desenvolvimento da teoria dos ecossistemas, parece óbvio que esta também tem enriquecido os modelos. Consequentemente, tornou-se quase impossível traçar uma linha 
MONTANHINI NETO, R. e OSTRENSKY, A. Revisão: Uso de modelos matemáticos para avaliação da influência de variáveis ambientais sobre o desenvolvimento de ostras no Brasil. PUBVET, Londrina, V. 6, N. 4, Ed. 191, Art. 1284, 2012.

divisória entre a teoria e a modelagem, principalmente depois do surgimento das funções meta (MANSSON e McGLADE,1993).

Os principais problemas apontados pelos críticos dizem respeito às generalizações dos modelos como: 1) na identificação dos componentes, pois geralmente o número de espécies e fatores ambientais é grande mesmo em sistemas considerados simples; 2) na agregação dos componentes funcionalmente similares numa caixa preta; e, consequentemente, na descrição imprecisa e incompleta das inter-relações, podendo acarretar noções tendenciosas do sistema (RIGLER e PETERS, 1991).

\section{Aplicação de Modelagem na Pesquisa em Ostreicultura}

A literatura referencia uma gama de trabalhos que, de alguma maneira, utiliza a métodos de modelagem para explicar e predizer o desenvolvimento biológico de ostras.

Desde o início da década de 80 estudos utilizavam modelos matemáticos, aliados a análises de regressão e estatística multivariada, para descrever a produção, crescimento e reprodução de ostras em cultivos e em bancos naturais (BROWN, 1988). Appeldroorn (1983) aplicou a análise de componentes principais e ponderou os resultados com equações de von Betarlanffy para examinar a influência de fatores ambientais sobre o crescimento de Mya arenaria em 25 diferentes regiões. Ulanowicz et al. (1980) derivou equações preditivas para fixação de ostras na baía de Chesapeake, EUA, com base temperatura da água e dados de salinidade. Na mesma região, o desenvolvimento produtivo de Crassostrea virginica foi correlacionado à precipitação, salinidade e produção de anos anteriores (Ulanowicz et al., 1982).

Pesquisadores têm buscado a melhor adaptação de dados de crescimento e reprodução de ostras aos principais modelos biológicos conhecidos (HALL, 1984; GANGNERY et al., 2003; TURECK et al., 2004; LIDDEL, 2008). Contudo,

para cada natureza de dados estudados e variáveis incluídos no modelo, há diferentes respostas na precisão de resultados. 
MONTANHINI NETO, R. e OSTRENSKY, A. Revisão: Uso de modelos matemáticos para avaliação da influência de variáveis ambientais sobre o desenvolvimento de ostras no Brasil. PUBVET, Londrina, V. 6, N. 4, Ed. 191, Art. 1284, 2012.

Tentando modelar cada ostra individualmente e cada um dos processos individuais celular dentro de cada ostra é uma tarefa muito árdua. O grande número de cálculos necessários para capturar todas as interações dentro de cada ostra e com cada ostra e seu ambiente é enorme, e desnecessariamente assim. O resultado final dessa abordagem seria um modelo que é tão complexo que é difícil trabalhar com e difícil de compreender como é a realidade. Quanto menos variáveis e interações que são usados em um modelo, mais fácil de compreender as respostas. No entanto, este deve ser equilibrado com o reconhecimento de que os sistemas biológicos e ecológicos são complexos e essa complexidade não pode ser ignorada (LIDDEL, 2008).

Encontrar o equilíbrio adequado entre simplicidade e complexidade é um dos desafios fundamentais no design de um modelo. A vantagem básica de complexidade limitante é que o modelo se torne mais fácil de desenvolver, mais fácil de trabalhar e seja mais adaptável às condições de pesquisa ou hipóteses que estão sendo testadas (CHWIF e PAUL, 2000).

Modelos ecofisiológicos de ostras, com base em balanços energéticos têm sido as ferramentas de monitoramento de eleição para prever o crescimento e reprodução, quando os dados estão relacionados à variáveis do meio ambiente (BARILLÉ et al., 1997; GRANT e BACHER, 1998; REN e ROSS, 2001; GANGNERY et al., 2003). Eles podem ser usados sozinhos ou em combinação com modelos gerais de dinâmica de população, de ecossistemas ou mesmo evolução (BACHER e GANGNERY, 2006).

Segundo Bourles et al. (2009), tais modelos têm duas grandes limitações. Em primeiro lugar, esses modelos só foram validados durante parte do ano, geralmente na fase de crescimento somático, a partir do final do inverno até o início do verão, e muito poucos modelos foram validados por mais de um ano. Em segundo lugar, esses modelos se mostraram altamente sensíveis e suas previsões são geralmente específicas para os locais de estudo para o qual foram desenvolvidos. O grande número de parâmetros destes modelos pode limitar sua utilização para novos ambientes, tornando-se difícil comparar os 
MONTANHINI NETO, R. e OSTRENSKY, A. Revisão: Uso de modelos matemáticos para avaliação da influência de variáveis ambientais sobre o desenvolvimento de ostras no Brasil. PUBVET, Londrina, V. 6, N. 4, Ed. 191, Art. 1284, 2012.

ecofisiologia de ostras entre diferentes áreas de produção, utilizando a mesma ferramenta.

O modelo de Dinâmica de Balanço Energético (KOOIJMAN, 1986 e 2000) tem sido adaptado para descrever a dinâmica de crescimento e reprodução de ostras do Pacífico ( $C$. gigas) cultivadas em diferentes regiões sob condições extremas de ambiente controlado e natural. Segundo Pouvreau et al. (2006), este modelo foi capaz de reproduzir quantitativamente com sucesso 0 crescimento, a reprodução e o período de desova. Os autores utilizaram a concentração de clorofila a como quantificação de alimento para o desenvolvimento do modelo. Bourlés et al. (2009) concluíram que a utilização de enumeração de fitoplâncton como quantificador de alimentos para este mesmo modelo (DEB), é possível se obter predições de crescimento e reprodução de $C$. gigas ainda mias precisas do aquelas obtidas pelos primeiros autores.

\section{CONSIDERAÇÕES FINAIS}

Resultados insatisfatórios de desempenho zootécnico e de desenvolvimento da ostreicultura como atividade econômica, principalmente entre os pequenos produtores, indicam uma falha no planejamento de cultivos e inadequação destes ao ambiente para criação. As flutuações de resultados zootécnicos e reprodutivos de ostras em cultivos estuarinos não podem ser atribuídas a uma causa única, mas sim ao resultado da influência de fatores biológicos, sazonais e processos ambientais, conjuntamente.

Para um molusco comercialmente tão importante, identificar e quantificar os fatores que levam a mudanças no desenvolvimento da população proporcionaria uma melhor compreensão do sistema, permitindo formar uma base para gestão eficiente do cultivo.

\section{REFERÊNCIAS}

ABSHER, T.M. Populações naturais de ostras do gênero Crassostrea do litoral do Paraná Desenvolvimento larval, recrutamento e crescimento. Tese Doutorado (Instituto Oceanográfico), Universidade de São Paulo, 1989. 
AGUDO, E.G. Guia de coleta e preservação de amostras de água. São Paulo, CETESB, 1988.

AKABOSHI, S. Notas sobre o comportamento da ostra japonesa, Crassostrea gigas (Thunberg, 1795), no litoral de São Paulo, Brasil. Boletim Instituto de Pesca, v.6, p. 93-104, 1979.

AKABOSHI, S.; PEREIRA, O.M. Ostreicultura na região lagunar-estuarina de Cananéia, São Paulo, Brasil. I. Captação de larvas de ostras, Crassostrea brasiliana (Lamarck, 1819), em ambiente natural. Boletim do Instituto de Pesca, 87-10, 1981.

ALVARENGA, L.; NALESSO, R.C. Preliminary assessment of the potential for mangrove oyster cultivation in Piraquê-açu river estuary (Aracruz, ES). Brazilian Archives of Biology and Technology, v.49 n.1, 2006.

ALVES, R. Estudo taxonômico de ostras do gênero Crassostrea Sacco, 1897, da região da Grande Florianópolis-Brasil. Dissertação de Mestrado (Pós-Graduação em Aquicultura), Universidade Federal de Santa Catarina, 2004.

ANDRIGUETTO FILHO, J.M.; MARCHIORO, N.P.X. Diagnóstico e Problemática para Pesquisa, p.159-194. In: C. Raynaut; M. Zanoni; P.C. Lana (Ed.). Desenvolvimento e Meio Ambiente: em busca da interdisciplinaridade. Curitiba, UFPR, 293p., 2002.

ANGELINI, R. Ecologia e modelagem matemática. Ciências Biológicas e do Meio Ambiente, vol. 2, n. 2, p.225-242, 2000.

APPELDOORN, R.S. Variation in the growth rate of Mya arenaria and its relationship to the environment as analyzed through Principal Components Analysis and the parameter of the von Bertalanffy equation. Fisheries Bulletin, v.81, p.75-84, 1983.

ARANA, L.V. Fundamentos de Aquicultura. UFSC, Florianópolis. 2004, 112p.

ARELLANO-MARTINEZ, M.; RACOTTA, I.S.; CEBALLS-VAZQUEZ, B.P.; ELORDUY-GARAY, J.F. Biochemical composition, reproductive activity and food availability of the lions paw scallop Nodipecten subnodosus in the Laguna Ojo de Liebre, Baja California, Mexico. Journal of Shellfish Research, v.23, p. 15-23, 2004.

BACHER, C.; GANGNERY, A. Use of dynamic energy budget and individual based models to simulate the dynamics of cultivated oyster population. Journal of Sea Research, v.56, p.140-155, 2006.

BALDWIN, R.L. Modeling ruminant digestion and metabolism. Chapman \& Hall, Londres, 1995. 578p.

BARILLÉ, L.; BOUGRIER, S.; GEAIRON, S.; ROBERT, J.M. Ecophysiological deterministic model for Crassostrea gigas in an estuarine environment. Aquatic Living Research, v.10, p.31-48, 1997.

BARLIZA, F.; QUINTANA, C. Contribución al desarrollo de la ostricultura en la ciénaga Grande de Santa Marta. Tese de Doutorado (Programa de Ingeniería Pesquera), Universidad del Magdalena, Santa Marta, 1992.

BARROSO, F.G.; LITTLEPAGE, J. Protocolo para análise de clorofila a e feopigmentos pelo método fluorimétrico. Vitória-ES, 1998, 18p.

BATALHA, M.O. A. Maricultura no Estado de São Paulo. $1^{\text {a }}$ ed. SEBRAE:GEPAI:GeNAQUI. São Paulo. 2002, 297p.

BAUTISTA, C. Moluscos: tecnologia de cultivo. Madrid, Ed. Mundi-Prensa, 1989, 167p.

BENINGER, P.G.; LUCAS, A. Seasonal variations in condition, reproductive activity, and gross biochemical composition of two species of adult clam reared in a common habitat: Tapes decussates L. and Tapes philippinarum. Journal of Exploratory Marine Biology and Ecology, n.79, p. 19-37, 1984. 
BENSON, D.A.; KARSCH-MIZRACHI, I.; LIPMAN, D.J.; OSTELL, J.; SAYERS, E.W. GenBank. Nucleic Acids Resource, n.39, Database issue, 2011.

BLACK, J.L. The evolution of animal growth models. In: MOUGHAN P.J. et al. Modeling growth in the pig. The Netherlands, Wageningen. 1995, p. 3-9.

BMLP - Brazilian Mariculture Linkage Program. Cultivo de Ostras. 2003 Disponível em: http://www.mpa.gov.br/mpa/seap/. Acesso em: 05/05/11.

BOURLÈS, Y.; ALUNNO-BRUSCIA, M.; POUVREAU, S.; TOlLU, G.; LEGUAY, D.; ARNAUD, C.; GOULLETQUER, P.; KOOIJMAN, S.A.L.M. Modelling growth and reproduction of the Pacific oyster Crassostrea gigas: Advances in the oyster-DEB model through application to a coastal pond. Journal of Sea Research, v.62, n.2-3, 2009.

BOYD, C.E.; WATTEN, B.J. Aeration systems in aquaculture. Aquatic Sciences, v.1, n.3, p.425-472, 1989.

BRITO, L. Efeito da salinidade sobre o crescimento da ostra nativa Crassostrea sp como subsídio ao desenvolvimento da maricultura de espécies nativas em mar aberto. Dissertação de Mestrado (Pós-Graduação em Sistema Costeiro e Oceânico), Universidade Federal do Paraná, 49p., 2008.

BROWN, J.R. Multivariate analyses of the role of environmental factors in seasonal and siterelated growth variation in the Pacific oyster Crassostrea gigas. Marine Ecology - Progress Series, v.45, p.225-236, 1988.

CADERNAS, E.B. Status of molluscan aquaculture on the Pacific coast of Mexico. Aquaculture, v.39, n.1-4, p.83-93, 1984.

CARDOSO, T.A.C. A construção da gestão compartilhada da Reserva Extrativista do Mandira, Cananéia-SP. Tese de Doutorado (Pós-Graduação em Ecologia) Universidade Federal de São Carlos. São Carlos, 176 p., 2008.

CHAPARRO, O.R. Manual de Cultivo de la ostra chilena (Ostrea chilensis). Ed. Universidad Austral de Chile, Instituto de Biología Marina. 1998, 16p.

CHRISTO, S.W. Biologia reprodutiva e ecologia de ostras do gênero Crassostrea (Sacco, 1897) na Baía de Guaratuba (Paraná - Brasil): um subsídio ao cultivo. Tese de Doutorado (PósGraduação em Ciências, área de concentração Zoologia), Universidade Federal do Paraná, 146 p., 2006.

CLÉDON, M., BRICHTOVA, J.L.; GUTIÉRREZ, J.L.; PENCHASZADEH, P.E. Reproductive cycle of the stout razor clam, Tagelus plebeius (Lightfoot, 1786), in the mar Chiquita coastal lagoon, Argentina. Journal of Shellfish Research, v.23, n.2, p.443-446, 2004.

COSTA, P.F. Biologia e tecnologia para o cultivo. In: Brasil. Ministérios da Marinha. Instituto Nacional de Estudos do Mar. Manual de Maricultura. Rio de Janeiro, cap. VIII, 1985.

CHWIF, L.; PAUL, R.J. On Simulation Model Complexity Proceedings of the 2000 Winter Simulation Conference. Fishwick eds., 2000.

DRIDI, S.; ROMDHANE, M.S. ; ELCAFSI, M. Seasonal variation in weight and biochemical composition of the Pacific oyster, Crassostrea gigas in relation to the gametogenic cycle and environmental conditions of the Bizert lagoon, Tunisia. Aquaculture, v.263, n.1-4, p. 238248, 2007.

ECO, U. Como se faz uma tese. Ed. Perspectiva. São Paulo. 1991, 96 p.

ERSE, E.B.; BERNARDES, M.A. Levantamento de estoques da ostra Crassostrea sp. em bancos naturais no litoral paranaense. Revista Biotemas, v.21, n.2, p.57-63, 2008.

ESCAPA, M.; ISACCH, J.P.; DALEO, P.; ALBERTI, J.; IRIBARNE, O.; BORGES, M.; SANTOS, E.P.; GAGLIARDINI, D.A.; LASTA, M. The distribution and ecological effects of the introduced Pacific 
oyster Crassostrea gigas (Thunberg, 1793) in northern Patagonia. Journal of Shellfish Research, v.23, n.1, p. 765-772, 2004.

ESTEVES, F. Fundamentos de Limnologia. $2^{\circ}$ ed. Rio de Janeiro, Ed. Interciência. 1998, 602 p.

FABIOUX, C.; HUVET, A.; SOUCHU, P.; PENNEC, M.; POUVREAU, S. Temperature and photoperiod drive Crassostrea gigas reproductive internal clock. Aquaculture, v.250, n.1-2, p. 458-470, 2005.

FAO. Global Aquaculture Production 1950-2009. Rome, Food and Agriculture Organization. 2009. Disponível em: www.fao.org/fishery/statistics. Acesso: 15/05/2011.

FAO-SOFIA. The State of World Fisheries and Aquaculture. 2002. Disponível em: http://www.fao.org/docrep/005/y7300e Acesso: 05/05/11.

FERNANDES, L.M.B.; SANCHES, R.J.C. Nota sobre a resistência às baixas salinidades da ostrade-mangue Crassostrea rhizophorae (Guilding, 1828). Anuário da Universidade Federal Rural do PE, n.5, p.61-79. 1980.

FERREIRA, J.F. Extensão na malacocultura e larvicultura de moluscos: o papel das instituições públicas. In: Sociedade Brasileira de Malacologia (Ed.). Malacologia Brasileira, Rio de Janeiro-RJ, p.109-122, 2006.

FRANCE, J.; THORNLEY, J.H.M. Mathematical models in agriculture. Londres (UK), Ed. Butterworth e Co. 1984, 352p.

GALTSOFF, P.S. The American oyster Crassostrea virginica (Gmelin). Fishery Bulletin, v.64, p. 11-28, 1964.

GALVÃO, M.S.N.; PEREIRA, O.M.; MACHADO, I.C.; HENRIQUES, M.B. Aspectos reprodutivos da ostra Crassostrea brasiliana de manguezais do estuário de Cananéia, SP ( $25^{\circ} \mathrm{S}, 48^{\circ} \mathrm{W}$ ). Boletim do Instituto de Pesca, v.26, n.2, p.147-162, 2000.

GANGNERY, A.; CHABIRAND, J.M.; LAGARDE, F.; LE GALL, P.; OHEIXA, J.; BACHER, C.; BUESTEL, D. Growth model of the Pacific oyster, Crassostrea gigas, cultured in Thau Lagoon (Méditerranée, France). Aquaculture, v.215, n.1-4, p.267-290, 2003.

GAUSE, G.F. The struggle for existence. Ed. Willians e Wilkins. Baltimore (USA). 1934, $135 \mathrm{p}$.

GIA - Grupo Integrado de Aquicultura, UFPR. Projeto de maricultura de ostras no complexo Lagamar-SP e Baía de Guaratuba-PR - Desenvolvimento de bases tecnológicas, ecológicas e mercadológicas para o cultivo. 2009. Disponível em: www.gia.org.br. Acesso: 05/05/11.

GOMEZ, H.; ARIAS, L.M.; PEREZ, C.; DUEÑAS, P.R.; FRIAS, J.A.; SILVA, L.M.; PEREA, L.S.; VALLEJO, A.; DAZA, P.V.; TORRES, M. Fundamentos de Acuicultura Marina. Santa Fe de Bogotá, Colombia, INPA. 1995, 543p.

GOULLETQUER, P. Cycle de reproduction naturelle de I $\square$ huître creuse Crassostrea gigas. In : La reproduction naturelle et contrôlée des bivalves cultivés en France, Nantes, France, Ifremer Rapport Interne DRV/RA/RST/97 - 11 RA /Brest, pp. 7-19, 1997.

GRANT, J. ; BACHER, C. Comparative models of mussel bioenergetics and their variation at field culture sites. Journal Exploratory Marine Biology and Ecology, v.219, p.21-44, 1998.

GUIMARÃES, I.M.; GOMES, A.I.; PEIXOTO, S.; OLIVEIRA, A. Influência da salinidade sobre a sobrevivência da ostra-do-mangue, Crassostrea rhizophorae. Arquivos de Ciências do Mar, v.41, n.1, p.118-122, 2008.

HALL, S. A multiple regression model of oyster growth. Fisheries Research, v.2, n.3, p.167$175,1984$. 
HARLOW, H.B.; IVEY, F.J. Accuracy, precision, and commercial benefits of growth modeling for broilers. Journal of Applied Poultry Research, v.3, n.4, p 391-402, 1994.

HENRIQUE, D.S. Desenvolvimento de modelos matemáticos para a predição da eficiência de utilização da energia para manutenção e ganho de peso em bovinos. Dissertação de Mestrado (Pós-Graduação em Zootecnia), Universidade Federal do Rio de Janeiro, 45 p., 2002.

HERAL, M. ; DESLOUS-PAOLI, J.M. Oyster culture in European countries. In: Estuarine and Marine Bivalve Mollusc Culture, Ed. by W. Menzel, CRC Press, New York, pp. 153-190, 1990.

IBGE - Instituto Brasileiro de Geografia e Estatística. Censo Agropecuário 2006. 2007. Disponível em: http://www.ibge.gov.br/home/estatistica/ economia/agropecuaria/censoagro/brasil_2006. Acesso: 05/05/10.

IGNACIO, B.L.; ABSHER, T.M.; LAZOSKI, C.; SOLÉ-CAVA, A.M. Genetic evidence of the presence of two species of Crassostrea (Bivalvia: Ostreidae) on the coast of Brazil. Marine Biology, v.136, n.6, p.987-991, 2000.

ISECMAR - Instituto Superior de Engenharia e Ciências do Mar. Relatório de Aulas Práticas: Anatomia dos Moluscos Bivalves. Disponível em: http://www.geocities.com/rui_biologia/docs. Acesso: 22/04/2011.

KINGSLAND, S.E. Modelingnature. Ed. Chicago, Chicago (USA), 1985. 376p.

KOOIJMAN, S.A.L.M. Energy budgets can explain body size relations. Journal of Theoretical Biology, v.121, p.269-282, 1986.

KOOIJMAN, S.A.L.M. Dynamic Energy and Mass Budgets in Biological Systems. Cambridge University Press, Cambridge, 424 p., 2000.

LAPE 'GUE, S.; BOUTET, I.; LEITÃO, A.; HEURTEBISE, S.; GARCIA, P.; THIRIOTUIE'VREUX, C.; BOUDRY, P. Trans-Atlantic distribution of a mangrove oyster species revealed by $16 \mathrm{~S}$ mtDNA and karyological analyses. Biological Bulletin, v.202, p. 232-242, 2002.

LEMOS, M.B.N.; I.A. NASCIMENTO; M.M.S. DE ARAÚJO; S.A. PEREIRA; I. BAHIA; D.H. SMITH.. The combined effects of salinity, temperature, antibiotic and aeration on larval growth and survival of the oyster Crassostrea rhizophorae. Journal of Shellfish Research, v.13, p. 187192, 1994.

LI, Q.; LIU, W.; SHIRASU, K.; CHEN, W.; JIANG, S. Reproductive cycle and biochemical composition of the Zhe oyster Crassostrea plicatula in an eastern coastal bay of China. Aquaculture, v.261, p. 752-759, 2006.

LIDDEL, M.K. A von Bertalanffy based model for the estimation of oyster (Crassostrea virginica) growth on restored oyster reefs in Chesapeake Bay. Tese de Doutorado (MarineEstuarine-Environmental Sciences), University of Maryland, EUA, 2008.

LOPES, G.R. Crescimento da ostra-do-mangue Crassostrea brasiliana (Lamarck, 1819) cultivada em dois ambientes no estado de Santa Catarina. Dissertação de Mestrado (PósGraduação em Aquicultura), Universidade Federal de Santa Catarina, 75 p., 2008.

LÓPEZ-FLORES, I.; RUIZ-REJÓN, C.; CROSS, I.; REBORDINOS, L.; ROBLES, F. NAVAJASPÉREZ, R.; HERRÁN, R. Molecular characterization and evolution of an interspersed repetitive DNA family of oysters. Genetica, v.138, n.11, p. 1211-1219, 2010.

LOUREIRO, C.F.B.; AZAZIEL, M.; FRANCA, N. Educação ambiental e conselho em unidades de conservação: aspectos teóricos e metodológicos. Ed. Ibase. Rio de Janeiro. 2007, 87p.

LOVATTO, P.A.; SAUVANT, D. Modelagem aplicada aos processos digestivos e metabólicos do suíno. Ciência Rural, v.31, n.4, p. 663-670, 2001. 
MANCERA, E.; MENDO, J. Population dynamics of the oyster Crassostrea rhizophorae from the Ciénaga Grande de Santa Marta, Colombia. Fisheries Research, v.26, n.1-2, p.139-148, 1996.

MANSSON, B.A.; McGLADE, J.M. Ecology, thermodynamics and H.T. Odum.s conjectures. Oecologia, v.93, p.582-596, 1993.

MCNAMARA, J.P.; FRANCE, J.; BEEVER, D. Modeling nutrient utilization in farm animals. Ed. CAB International, Londres (UK). 2000, 400p.

MELO, A.G.; VARELA, E.S.; BEASLEY, C.R.; SCHNEIDER, H.; SAMPAIO, I.; GAFFNEY, P.M.; REECE, K.S.; TAGLIARO, C.H. Molecular identification, phylogeny and geographic distribution of Brazilian mangrove oysters (Crassostrea). Genetic Molecular Biology, v.33, n.3, p. 567572, 2010.

MELO, C.M.R.; SILVA, F.C.; GOMES, C.H.A.M.; SOLÉ-CAVA, A.M.; LAZOSKI, C. Crassostrea gigas in natural oyster banks in southern Brazil. Biological Invasions, n.12, v.3, p. 441-449, 2009.

MIOSSEC, L.; DEUFFM, R.M. ; GOULLETQUER, P. Alien species alert: Crassostrea gigas (Pacific oyster). ICES Cooperative Research Report. Rapport des Recherches Collectives, n.299, 46 p., 2009.

MIRANDA, M.B.B.; GUZENSKI, J. Cultivo larval da ostra do mangue, Crassostrea rhizophorae (Guilding, 1828), em diferentes condições de temperatura, salinidade e densidade. Arquivos de Ciências do Mar, UFC, v.32, p.73- 84, 1999.

NALESSO, R.C; PARESQUE, K.; PIUMBINI, P.P; TONINI, J.R.F.; ALMEIDA, L.G.; NÍCKEL, V.M. Oyster spat recruitment in Espírito Santo State, Brazil, using recycled materials. Brazilan Journal of Oceanography, v.56, n.4, p. 281-288, 2008.

NASCIMENTO, I.A. Crassostrea rhizophorae (Guilding) and C. brasiliana (Lamarck) in South and Central America. Chapter 10. In Estuarine and marine bivalve mollusk culture. Winston Menzel, Flórida, USA, CRC Press Inc. pp. 125-134, 1991

NASCIMENTO, I.A.; S.A., PEREIRA. Cultivo da ostra de mangue Crassostrea rhizophorae (Guilding 1828). In: POLI, C. R.et al. (Eds.). Aquicultura. Florianópolis: Multitarefa Editora. p. 267-288, 2004.

NEHRING, S. Oyster beds and Sabellaria reefs. In: De Jong, F., Bakker, J.F., van Berkel, C.J.M., Dankers, N.M.J.A., Dahl, K., Gätje, C., Marencic, H. and Potel, P. (eds.), Wadden Sea Quality Status Report. Wadden Sea Ecosystem, n.9, p. 146-147, 1999.

NIMPIS. Pacific oyster Crassostrea gigas. - In: C.L. Hewitt; R.B. Martin; C. Sliwa; F.R, McEnnulty; N.E. Murphy; T. Jones \& S. Cooper (eds), National Introduced Marine Pest Information System, 2002. Disponível em: http://www.marine.csiro.au Acessado em 29/06/2010.

OSTRENSKY, A.; BOEgER, W. A.; CHAMMAS, M. A. Potencial para o desenvolvimento da aquicultura no Brasil. In: Ostrensky, A.; Borghetti, J.R.; Soto, D. Aquicultura no Brasil: o desafio é crescer. Brasília: SEAP, 2008. p.159-182.

PEREIRA, O.M.; HENRIQUES, M.B.; MACHADO, I.C. Estimativa da curva de crescimento da ostra Crassostrea brasiliana em bosques de mangue e proposta para sua extração ordenada no estuário de Cananéia, SP, Brasil. Boletim do Instituto de Pesca, v.29, n.1. p.19-28, 2003.

PIE, M.R.; RIBEIRO, R.O.; BOEGER, W.A.; OSTRENSKY, A.; FALLEIROS, R.M.; ANGELO, L. A simple PCR-RFLP method for the discrimination of native and introduced oyster species (Crassostrea brasiliana, C. rhizophorae and C. gigas; Bivalvia: Ostreidae) cultured in Southern Brazil. Aquaculture Research, v.37, p.1598-1600, 2006.

POLI, C.R. Biologia e cultivo de ostras. Ed. UFSC. Florianópolis. 1998, 70 p. 
PORTELLA, C.P. Avaliação da qualidade da ostra nativa Crassostrea brasiliana congelada em concha em função da composição química e análise sensorial. Dissertação de Mestrado (Pós-Graduação em Aquicultura), Universidade Estadual Paulista, 75 p., 2005.

POUVREAU, S.; BOURLESA, Y.; LEFEBVREC, S., GANGNERYD, A.; ALUNNO-BRUSCIAB, M. Application of a dynamic energy budget model to the Pacific oyster, Crassostrea gigas, reared under various environmental conditions. Journal of Sea Research, v.56, n.2, p.156-167, 2006.

POWELL, E.N., BOCHENEK, E.A., KLINCK, J.M.; HOFMANN, E.E. Influence of food quality and quantity on the growth and development of Crassostrea gigas larvae: a modelling approach. Aquaculture, v.210, p. 89-117, 2002.

POWELL, E.; KLINCK, J.; HOFMANN, E.; BOCHENEK, E. Food quality and feeding strategies in hatchery rearing of pacific oyster Crassostrea gigas larvae: a modelling approach. Journal of Shellfish Research, v.1, p.604., 2000.

PUGIALLI, R. Glossário Oceanográfico Ilustrado. Ed. Âmbito Cultural, Rio de Janeiro. 2000, $567 p$.

PROENÇA, C.E.M. Plataforma do agronegócio da malacocultura. Brasília, CNPQ/DPA/MAPA, 2001.

RAMOS, R.S.; CASTRO, A.C.L. monitoramento das variáveis físico-químicas no cultivo de Crassostrea rhizophorae (Guilding, 1928) no estuário de Paquatiua-Alcântara/Ma, Brasil. Boletim do Laboratório de Hidrobiologia, UFMA, v.17, p.29-42, 2004.

REN, J.S.; MARSDEN, I.D.; ROSS, A.H.; SCHIEL, D.R. Seasonal variation in the reproductive activity and biochemical composition of the Pacific oyster (Crassostrea gigas) from the Marlborough Sounds, New Zealand. New Zealand Journal of Marine and Freshwater Research, v.37, n.1, p. 171-182, 2003.

REN, J.S.; ROSS, A.H. A dynamic energy budget model of the Pacific oyster Crassostrea gigas. Ecology Modeling, v.142, p.105-120, 2001.

RIGLER, F.H.; PETERS, R.H. Science and limnology., Ecology Institute, Germany. 1991, $428 \mathrm{p}$.

RIOS, E.C. Seashells of Brazil. Ed. Fundação Universidade do Rio Grande., Rio Grande. 1994, 492p.

RONDÓN, E.O.O.; MURAKAMI, A.E.; SAKAGUTI, E.S. Modelagem computacional para produção e pesquisa em avicultura. Brazilian Journal of Poultry Science, v.4, n.1, p.199-207, 2002.

SAUCEDO, P.; RACOTTA, I.; VILLARREAL, H.; MONTEFORTE, M. Seasonal changes in the histological and biochemical profile of the gonad, digestive gland and muscle of the calafia mother-of-pearl oyster, Pinctada mazatlanica (Hanley, 1856) associated with gametogenesis. Journal of Shellfish Research, v.21, p. 127-135, 2002.

SANTOS, F.M.T.; GRECA, I.M. Promovendo aprendizagem de conceitos e de representações pictóricas em química com uma ferramenta de simulação computacional. Revista Electrónica de Enseñanza de Ciências, v.4, n.1, 2005.

SHUMWAY, S.E. Natural environmental factors. In: Kennedy, V.S., Newell, R.I.E., Eble, A.F. (Eds.), The Eastern Oyster Crassostrea virginica. Maryland Sea Grant College, College Park, pp. 467-513, 1996.

SIQUEIRA, K.L.F.; ARAÚJO, E.D.; PADILHA, F.F.; ARAÚJO, J.M.E. Aspectos Sanitários da água e das ostras nativas do gênero Crassostrea cultivadas no Rio Vaza Barris. Revista Eletrônica de Biologia, v.3, n.2, p.76-88, 2010.

SILVA, N.J.R. Sistema local de inovação da piscicultura. Panorama da Aqüicultura, v. 14, p. 37-41, 2004. 
SOUZA FILHO, J. Custo de produção da ostra cultivada. Instituto Cepa/SC, Cadernos de indicadores agrícolas, Florianópolis. 2003, 23p.

SPEDDING, C.R.W. General aspects of modeling and its application in livestock production. In: Modeling of livestock production systems, Ed. Kluwer Academic, Brussels (Belgium), p. 3-9, 1988.

STARFIELD, A.M.; BLELOCH, R. Building models for conservation and wildlife management., Macmillan Publishing Company/Collier Macmillan Publishers, Nova York/London. 1986, 245p.

STEPHEN, D. The reproductive biology of the indian oyster Crassotrea madrasensis: Gametogenic cycle and biochemical levels. Aquaculture, v.21, p. 147-153, 1980.

TAYLOR, A.C.; VENN, T.J. Seasonal variation in weight and biochemical composition of the tissues of the queen scallop Chlamys opercularis from the Clyde Sea area. Journal of Marine Biology Association, n.59, p. 605-621, 1979.

TURECK, C.R.; OLIVEIRA, T.M.N.; CREMER, M.J.; BREITER, R.; NEESSE, T.; TORRENS, B.M.O.; MARCUCCI, A.; AMARAL, E.B. Avaliação do crescimento em Crassostrea gigas (molusca, bivalve) cultivada na Baía da Babitonga, litoral norte do Estado de Santa Catarina. Revista da Univille, v.9 (edição especial), p.17-26, 2004.

ULANOWICZ, R.E.; AH, M.L.; VIVIAN, A.; HEINLE, D.R.; RICHKUS, W.A.; SUMMERS, J.K. Identifying climatic factors influencing commercial fish and shellfish landings in Maryland. Fisheries Bulletin, v.80, p.611-619, 1982.

ULANOWICZ, R.E.; CAPLINS, W.C.; DUNNINGTON, E.A. The forecasting of oyster harvest in Central Chesapeake Bay. Estuarine and Coast Marine Science, v.2, p.101-106. 1980.

VARELA, E.S.; BEASLEY, C.R.; SCHNEIDER, H.; SAMPAIO, I.; MARQUES-SILVA, N.S.; TAGLIARO, C.H. Molecular phylogeny of mangrove oysters (Crassostrea). Journal of Molluscan Studies, v.73, p.229-234, 2007.

VILANOVA, M.F.V.; CHAVES, E.M.B. Contribuição para o conhecimento da viabilidade do cultivo de ostra-do-mangue, Crassostrea rhizophorae (Guilding,1828, Mollusca: Bivalvia), no estuário do rio Ceará, Ceará, Brasil. Arquivos de Ciências do Mar, Fortaleza, v.27, p.111-125, 1988.

VINATEA, L.A. Aquicultura e desenvolvimento sustentável: subsídios para a formulação de políticas de desenvolvimento da aquicultura brasileira. UFSC, Florianópolis. 1999, 310p.

VINATEA, L.A. Princípios químicos da qualidade da água em aquicultura. UFSC, Florianópolis. 1997, 166p.

VINATEA, L.; VIEIRA, P.H.F. Modos de apropriação e gestão patrimonial de recursos costeiros: o caso do cultivo de moluscos na Baía de Florianópolis, SC. Boletim do Instituto de Pesca, São Paulo, v.31, n.2, p.147-154, 2005.

VON BERTALANFFY, L. Untersuchgen uber die Gesetzchkeiten des wachstms. Allgemie Grundlagen der Theorie. Original, Roux. Arch., 1934. Tradução: Teoria geral dos sistemas. Ed. Vozes, Rio de Janeiro. 1977, 131p.

WAKAMATSU, T. A ostra de Cananéia e seu cultivo. Superintendência do Desenvolvimento do Litoral Paulista/Instituto Oceanográfico, USP, São Paulo. 1973, 141p.

ZANDEE, D.I.; KLUYTMANS, J.H.; ZURBURG, W.; PIETERS, H. Seasonal variations in biochemical composition of Mytilus edulis with reference to energy metabolism and gametogenesis. Netherland Journal of Sea Research, n.14, p. 1-29, 1980. 